\title{
MULTIKULTURALISME DALAM SASTRA INDONESIA SEBAGAI BAHAN AJAR APRESIASI SASTRA
}

\author{
Esti Ismawati ${ }^{1}$, K.A. Anindita ${ }^{2}$, Rintik $S^{3}$, Asriana $S^{4}$ \\ ${ }^{1}$ PB Pascasarjana Unwidha \\ ${ }^{2}$ LD Pascasarjana UNS \\ ${ }^{3}$ PB Pascasarjana Unwidha \\ ${ }^{4}$ PB Pascasarjana Unwidha \\ ${ }^{1}$ estisetyadi@gmail.com
}

\begin{abstract}
Abstrak
Sebagai bangsa yang multikultur, Indonesia mempunyai potensi perpecahan dan konflik etnik yang cukup besar jika tidak dikelola dengan baik. Tulisan ini mendeskripsikan nilai-nilai multikultural dalam sastra Indonesia sebagai bahan pembelajaran apresiasi sastra di SMA, yang dapat menjadi pemantik bagi terbentuknya karakter multikultur. Lewat apresiasi sastra diyakini penanaman karakter tepat sasaran (efektif) karena sastra bersentuhan dengan nilai-nilai kemanusiaan. Metode yang digunakan adalah deskriptif dengan teknik simak catat. Data diambil dari empat karya sastra Indonesia, yakni satu cerpen terpilih dan tiga novel. Data dianalisis dengan pendekatan struktural-semiotik. Dari hasil analisis dapat disimpulkan bahwa cerpen "Seribu Kunang-kunang di Manhattan", karya Umar Kayam, novel "Salah Asuhan" karya Abdul Moeis, dan novel "Namaku Hiroko" karya Nh Dini, mengandung nilai-nilai kesederajatan (egalitarian), keberagaman, dan karakter multikulturalis yang baik pada tokoh utamanya, layak dijadikan bahan ajar apresiasi sastra di tingkat SMA.
\end{abstract}

Kata kunci: multikultural, bahan ajar, apresiasi sastra

\begin{abstract}
As a multicultural nation, Indonesia has considerable potential for disunity and ethnic conflicts if the various differences are not managed well. This paper describes multicultural values in Indonesian literature as teaching and learning materials for literary appreciation in high school, which can be a trigger for the formation of multicultural characters. Through literary appreciation it is believed that character inculcation is right on target (effective) because literature is in touch with human values. The method used was descriptive with the note taking technique. Data were taken from four Indonesian literary works, namely one selected short story and three novels. Data were analyzed by a structuralsemiotic approach. From the results of the analysis it can be concluded that the short story "Seribu Kunang-kunang di Manhattan" by Umar Kayam, the novel "Salah Asuhan" by Abdul Moeis, and the novel "Namaku Hiroko" by Nh Dini contain the values of equality (egalitarian), diversity, and multicultural characters that are good for the main character, are worthy of being used as literary appreciation teaching materials at the high school level.
\end{abstract}

Keywords: multiculturalism, material learning, literature appreciation 


\section{PENDAHULUAN}

Indonesia dikenal sebagai negara kepulauan terbesar di dunia, dengan berbagai suku bangsa, etnis budaya, corak bahasa daerah, dan letak geografis yang memanjang dari Sabang sampai Merauke, dari Timor hingga pulau Rote, dengan garis pantai terpanjang ketiga di dunia. Sebagai negara bangsa, Indonesia dibangun di atas keberagaman etnis, agama, ras, adat, bahasa. Kondisi ini sangat rentan terhadap isu-isu yang menyangkut dilema multikultur, dan berbagai konflik yang timbul karena perbedaan (etnis, agama, ras, adat, bahasa) tersebut. Jika tidak dikelola dengan baik akan menimbulkan pergesekan, karena satu sama lain tidak saling memahami, menghargai, menghormati. Sebagaimana dikatakan Firdaus, hal ini kerap muncul karena faham antoposentris yang disebabkan minimnya pengenalan kebudayaan di luar kebudayaannya sendiri (Firdaus, dkk, 2015: 1755). Kenyataannya, memang pemahaman mahasiswa dan siswa SMA-SMK-MA tentang multikulturalisme masih minim (Kompas, 2010) (https://nasional.kompas.com 30 Oktober 2010). Untuk menanamkan kesadaran multikulturalisme, diusulkan sistem pendidikan perlu diperbaiki dengan memberikan penekanan pada pendidikan multikultural (Suparlan, 2002). Multikulturalisme itu sendiri menyangkut suatu pemahaman, penghargaan, serta penilaian atas sikap dan perilaku yang menjunjung tinggi pada nilai-nilai kebhinekaan di dalam kesederajatan, dengan mempertebal rasa persamaan, mempersempit rasa perbedaan (Lubis, 2006). Penanaman nilai-nilai multikulturalisme kepada siswa, mahasiswa, dan remaja amat perlu, salah satunya melalui kajian sastra di bangku sekolah dan di luar sekolah (Ismawati, 2017).

Bahan ajar sastra di lapangan sudah banyak, namum bahan ajar untuk membelajarkan karakter multikultural harus dikaji sendiri oleh guru atau dosen yang akan mengajar. Bahan ajar adalah fakta, konsep, prinsip, atau prosedur yang akan digunakan sebagai sarana pembelajaran (Ismawati, 2016: 30). Bahan ajar adalah seperangkat sarana atau alat pembelajaran yang berisikan materi pembelajaran, metode, batasan-batasan, dan cara mengevaluasi yang didesain secara sistematis dan menarik dalam rangka mencapai tujuan yang diharapkan, yaitu mencapai kompetensi 
atau subkompetensi dengan segala kompleksitasnya (Arumdyahsari, 2016: 1). Bahan ajar yang sistematis dan menarik akan membuat pembelajaran menjadi indah dan bermakna.

\section{Multikultural dan Pluralisme Budaya di Indonesia}

Pluralisme adalah paham bahwa masyarakat Indonesia adalah masyarakat majemuk yang beraneka ragam suku bangsa dan budayanya yang diikat dalam bhineka tunggal ika yang multicultural (Azra, 2007). Sebagai sebuah ide atau ideologi, multikulturalisme terserap dalam berbagai interaksi yang ada dalam berbagai struktur kegiatan kehidupan masyarakat yang tercakup dalam kehidupan sosial, kehidupan ekonomi dan bisnis, kehidupan politik, dan berbagai kegiatan lainnya dalam masyarakat yang bersangkutan (Suparlan, 2002: 98). Konsep multikulturalisme tidak dapat disamakan dengan konsep keanekaragaman secara sukubangsa atau kebudayaan sukubangsa yang menjadi ciri masyarakat majemuk, karena multikulturalisme menekankan keanekaragaman kebudayaan dalam kesederajatan (Watson, 2000 dalam Suparlan, 2002: 99).

Untuk memahami multikulturalisme, diperlukan landasan pengetahuan berupa bangunan konsep-konsep yang relevan dengan, dan mendukung keberadaan, serta berfungsinya multikulturalisme dalam kehidupan manusia, antara lain demokrasi, keadilan dan hukum, nilai-nilai budaya dan etos, kebersamaan dalam perbedaan yang sederajat, sukubangsa, kesukubangsaan, kebudayaan sukubangsa, keyakinan keagamaan, ungkapan-ungkapan budaya, domain privat dan publik, HAM, hak budaya komuniti, dan konsep-konsep lainnya yang relevan (Fay 1996; Rex 1985; dalam Suparlan 2002: 100).

Kajian-kajian mengenai corak kegiatan, yaitu hubungan antarmanusia dalam berbagai manajemen pengelolaan sumber-sumber daya akan merupakan sumbangan yang penting dalam upaya mengembangkan dan memantapkan multikulturalisme dalam kehidupan bermasyarakat, berbangsa, dan bernegara bagi Indonesia. Salah satu isu yang cukup penting untuk diperhatikan adalah kajian-kajian mengenai manajemen pengelolaan sumber-sumber daya (Suparlan, 2002: 100). Tidak jarang persoalan 
manajemen sumber-sumber daya ini menyebabkan munculnya berbagai konflik yang berkepanjangan di berbagai daerah dengan melihat munculnya demo-demo yang cukup panas dan sensitif.

Bersamaan dengan upaya-upaya tersebut, ada usulan bahwa sebaiknya Depdiknas R.I. mengadopsi pendidikan multikulturalisme untuk diberlakukan dalam pendidikan sekolah, dari tingkat SD sampai dengan SLTA. Multikulturalisme sebaiknya masuk dalam kurikulum sekolah, dan pelaksanaannya dapat dilakukan sebagai pelajaran ekstra kurikuler atau menjadi bagian dari kurikulum sekolah (khususnya untuk daerah-daerah bekas konflik berdarah antarsukubangsa, seperti di Poso, Kalimantan Barat, Kalimantan Tengah, dan berbagai tempat lainnya) (Suparlan 2002: 101). Usulan ini sangat menarik dan layak untuk diwujudkan.

Multikulturalisme adalah istilah yang digunakan untuk menjelaskan pandangan seseorang tentang ragam kehidupan di dunia, ataupun kebijakan kebudayaan yang menekankan tentang penerimaan terhadap adanya keragaman, dan berbagai macam budaya (multikultural) yang ada dalam ehidupan masyarakat menyangkut nilai-nilai, sistem, budaya, kebiasaan, dan politik yang dianut mereka (Wikipedia Indonesia, diunduh 10 Januari, 2019).

Multikulturalisme pada dasarnya adalah pandangan dunia yang kemudian dapat diterjemahkan dalam berbagai kebijakan kebudayaan yang menekankan penerimaan terhadap realitas keagamaan, pluralitas, dan multikultural yang terdapat dalam kehidupan masyarakat. Multikulturalisme dapat juga dipahami sebagai pandangan dunia yang kemudian diwujudkan dalam kesadaran politik (Azra, 2007).

Masyarakat multikultural adalah suatu masyarakat yang terdiri dari beberapa macam komunitas budaya dengan segala kelebihannya, dengan sedikit perbedaan konsepsi mengenai dunia, suatu sistem arti, nilai, bentuk organisasi sosial, sejarah, adat serta kebiasaan. "A Multicultural society, then is one that includes several cultural communities with their overlapping but none the less distinc conception of the world, system of meaning, values, forms of social organizations, historis, customs and practices" (Parekh, 1997 dalam Azra, 2007). 
Multikulturalisme mencakup suatu pemahaman, penghargaan serta penilaian atas budaya seseorang, serta suatu penghormatan dan keingintahuan tentang budaya etnis orang lain (Lubis, 2006:174) Sebuah ideologi yang mengakui dan mengagungkan perbedaan dalam kesederajatan baik secara individual maupun secara kebudayaan (Suparlan, 2002).

Multikulturalisme mencakup gagasan, cara pandang, kebijakan, penyikapan dan tindakan, oleh masyarakat suatu negara, yang majemuk dari segi etnis, budaya, agama dan sebagainya, namun mempunyai cita-cita untuk mengembangkan semangat kebangsaan yang sama dan mempunyai kebanggan untuk mempertahankan kemajemukan tersebut (Harahap, 2007 dalam Azra, 2007).

\section{Multikultural dalam Sastra Indonesia}

Masyarakat Indonesia merupakan masyarakat dengan tingkat keanekaragaman yang sangat kompleks. Masyarakat dengan berbagai keanekaragaman tersebut dikenal dengan istilah masyarakat multikultural. Menurut Linton (dalam Ismawati, 2012), konsep masyarakat seperti ini jika digabungkan dengan multikurtural memiliki makna yang sangat luas dan diperlukan pemahaman yang mendalam.

Multikulturalisme yang terbentuk di Indonesia merupakan akibat dari kondisi sosio-kultural maupun geografis yang begitu beragam dan luas. Menurut kondisi geografis, Indonesia memiliki banyak pulau di mana setiap pulau dihuni oleh sekelompok manusia yang membentuk suatu masyarakat. Dari masyarakat ini terbentuklah sebuah kebudayaan mengenai masyarakat itu sendiri. Tentu saja hal ini berimbas pada keberadaan kebudayaan yang sangat banyak dan beraneka ragam. Multikultural dapat terjadi di Indonesia karena (1) Letak geografis Indonesia, dapat dilihat pada novel Namaku Hiroko (Dini, 2003); (2) perkawinan campur, dapat dilihat pada novel Salah Asuhan (Moeis, 2000); (3) Iklim, dapat dilihat pada cerpen Seribu Kunang-kunang di Manhattan (Kayam, 2003). Dan ini menarik untuk dijadikan bahan ajar sastra Indonesia (Ismawati, 2013).

Dalam konsep multikulturalisme, terdapat kaitan yang erat bagi pembentukan masyarakat yang berlandaskan bhineka tunggal ika serta mewujudkan suatu 
kebudayaan nasional yang menjadi pemersatu bagi bangsa Indonesia. Namun, dalam pelaksanaannya masih terdapat berbagai hambatan yang menghalangi terbentuknya sikap multikulturalis di masyarakat dalam bingkai NKRI (Negara Kesatuan Republik Indonesia) karena banyaknya persoalan sosial budaya yang muncul akibat berbagai hal, salah satunya masih tingginya kesenjangan sosial.

Menurut Budiman (2008) dalam konteks ini kita agak terhibur karena para penulis muda saat ini memiliki perhatian dan keprihatinan besar pada berbagai persoalan sosial dan kemanusiaan yang terjadi di negeri ini. Mereka menulis tentang penindasan dan ketidakadilan di Papua, Bali dan Lombok; tentang kekerasan dan intoleransi di Ambon dan Aceh; dan tentang sejarah yang dimanipulasi dan diselewengkan demi kepentingan kekuasaan. "Kita cukup menyimak dengan saksama apa yang dituangkan oleh penulis-penulis kontemporer, seperti Okky Madasari, Erni Aladjai, Zubaidah Djohar, Anindita Thayf, Steve Elu, dan Astina Triutami” tentang kebebasan dari kebencian, cinta di tengah kecamuk kekerasan, penolakan untuk melupakan kesewenang-wenangan, perlawanan terhadap ketidakadilan, dan perjuangan hidup orang-orang terbuang, untuk dapat menangkap adanya keterlibatan yang intens dan sejati dalam karya-karya mereka pada pencarian jalan keluar yang bermartabat bagi segudang persoalan bangsa (Budiman, 2008).

Sayangnya, apa yang ditulis para penulis muda dalam karya mereka belum tersosialisasikan dengan baik di kalangan siswa, mahasiswa, dan remaja, sehingga diperlukan kajian tentang nilai-nilai yang terkait dengan sastra dan multicultural, tentang persoalan kesenjangan social, tentang sikap yang harus ditumbuhkan sebagai bangsa yang multikultur agar persoalan-persoalan social tidak berujung pada kekerasan yang destruktif. Permasalahan yang akan dijawab tulisan ini adalah, bagaimana nilainilai multicultural terefleksi dalam karya sastra Indonesia? Apakah nilai-nilai tersebut dapat dijadikan bahan ajar apresiasi sastra agar dapat menjadi pemantik bagi nyala api multikulturalis Indonesia? 
Tulisan ini mendeskripsikan nilai-nilai multikultural dalam sastra Indonesia sebagai bahan pembelajaran apresiasi sastra di SMA, yang dapat menjadi pemantik bagi terbentuknya karakter multikultur.

\section{METODE}

Penelitian ini menggunakan pendekatan kualitatif dengan analisis deskriptif mengkaji multikulturalisme dalam teks sastra Indonesia. Fokus kajiannya adalah pertimbangan atau kritik sastra. Dalam sejarah kritik sastra, terdapat banyak perspektif, pendekatan, dan teori yang digunakan untuk meneliti, mengulas, dan menilai karya sastra. Beberapa ahli sastra menyusun logical frame work analysis, yang dapat dipandang sebagai sebuah paradigma. Hingga saat ini ada tiga kerangka kerja sistematis penelitian sastra yang dikemukakan oleh empat pakar dalam tiga paradigma Ilmu Sastra, yakni Paradigma Renne Wellek \& Austin Warren, Paradigma Ronald Tanaka, dan Paradigma M. H. Abrams. Cara pandang yang dipilih peneliti berimplikasi kuat pada corak pendekatan dalam penelitian yang dilakukan, seperti jenis persoalan empiris dan rekonstruksi teori yang digunakan (Taum, 2017: 2; Ratna, 2008 ). Penelitian ini menggunakan paradigma Abram dengan penekanan pada karya dan pembaca. Objek kajiannya adalah cerpen "Seribu Kunang-kunang di Manhattan" (2000), karya Umar Kayam, novel "Salah Asuhan" karya Abdoel Moeis, dan novel "Namaku Hiroko" karya Nh Dini. Cara mengkajinya dengan menafsir secara structural semiotik.

Adalah Stephen Greenblatt -pencetus kajian new historicism - yang menawarkan perspektif baru dalam kajian sastra Renaissance, yakni dengan menekankan keterkaitan teks sastra dengan berbagai kekuatan sosial, ekonomi dan politik yang melingkupinya (Taum, 2017: 5). Kajian ini juga akan melihat realitas berbagai kekuatan sosial, ekonomi (yang disederhanakan guna kepentingan bahan ajar SMA) dalam semangat kesederajatan dan keberagaman (apa yang disebut multikulturalisme) dalam teks sastra Indonesia, khususnya dalam cerpen dan novel.

Sesuai dengan karakternya, secara imajinatif novel memiliki kemampuan yang luas dalam menceritakan seluk beluk kehidupan sosial (masyarakat) sehingga dalam 
hal ini novel ditempatkan sebagai cermin masyarakat, dan realitas fiksi secara signifikan dapat diacukan pada realitas atau peristiwa sosial-politik dalam masyarakat. Dengan demikian, pembicaraan tidak hanya mengeksplorasi sesuatu yang bersifat endoforis, dunia internal yang dibangun di dalam novel, kajian ini merefleksikannya pada sesuatu yang eksoforis, yakni suatu kajian yang mengaitkannya dengan dunia eksternal di luar dunia yang dibangun oleh fiksi (Salam, 2008: 2).

Semua macam teks, termasuk diskursus akademis suatu zaman, muncul di bawah model teoretis zamannya. Sastra tidak dapat lagi dipandang sebagai sesuatu yang lari dari sejarah dan terapung di udara seperti sebuah entitas yang terasing dan terpisah (bandingkan: Foucault, 2011: 85; Sudikan, 2019). Dalam praktiknya, beberapa pakar kritik sastra diskursif membaca konteks kesejarahan melalui dokumen-dokumen seperti hukum dan kedokteran, anekdot, kisah perjalanan, etnologis dan antropologis, dan tentu saja teks-teks sastra (Taum, 2017: 5).

Banyak cara yang dapat digunakan untuk mengenalkan karakter multikulturalis kepada siswa (Sudikan, 2018), salah satunya melalui pengenalan local wisdom dalam sastra. Sebagaimana dikatakan oleh Tina Kartika (2016) if local wisdom actually exists in everyday life, the nation of Indonesia has carved beauty behave in civilization itself. The local wisdom of the nation begins values, the rule in the family, and then developed in the community. A positive value of local wisdom is the identifier of civilized society and the need to preserve Indonesia (Kartika, 2016: 1). Dengan mengenal local wisdom dalam sastra akan memperkuat karakter multikultural siswa, yang pada gilirannya tidak mudah terpecah belah oleh berbagai isu perbedaan.

\section{HASIL DAN PEMBAHASAN}

\section{Multikultural dalam Cerpen Seribu Kunang-kunang di Manhattan Karya Umar}

\section{Kayam}

Cerpen Seribu Kunang-kunang di Manhattan atau disingkat SKM (Kayam, 2003) berkisah tentang pemuda Marno dari Indonesia yang sedang sekolah di Amerika dengan seorang perempuan Amerika yang sudah berkeluarga tetapi bercerai, bernama 
Jane. Marno masih tetap kuat memegang adat budaya Indonesia, sementara Jane suka menggoda Marno yang mulai dihinggapi rasa sunyi:

"Marno mulai memasang rokok lalu pergi berdiri di dekat jendela. Langit bersih malam itu, kecuali di sekitar bulan. Beberapa awan menggerombol di sekeliling bulan hingga cahaya bulan jadi suram karenanya. Dilongokknannya kepalanya ke bawah dan satu belantara pencakar langit tertidur di bawahnya. Sinar bulan yang lembut itu membuat seakan-akan bangunan-bangunan itu tertidur dalam kedinginan. Rasa senyap dan kosong tiba-tiba terasa merangkak ke dalam tubuhnya". (Kayam, 2003. SKM, halaman 2).

Cerita berawal tentang perbedaan persepsi. Jane menganggap bulan itu berwarna ungu, sementara Marno bersikukuh jika bulan itu berwarna kuning keemasan. Sikap Marno kepada Jane bisa dijadikan teladan, bahwa jauh dari isteri tidak harus melupakan. Jauh dari tanah air tidak harus melupakan. Jauh dari segalanya masih dapat mempertahankan kepercayaan, tidak merusaknya. Apalagi jika dekat tak berjarak. Kita dapat saling menghormati perbedaan. Inilah prinsip-prinsip karakter multikulturalis. Tidak memaksakan orang lain agar mau sama dengan kita. Tidak menjadikan diri paling benar dan yang lain salah. Sikap Marno yang setia dan nasionalis masih dapat dibuktikan pada kutipan di bawah ini :

"Lampu-lampu yang berkelipan di belantara pencakar langit yang kelihatan dari jendela mengingatkan Marno pada ratusan kunang-kunang yang suka bertabur malammalam di sawah embahnya di desa".

(Kayam, 2003. SKM, halaman 3).

"Marno tidak menjawab karena tiba-tiba saja dia merasa seakan-akan istrinya ada di dekat-dekat dia di Manhattan malam itu. Adakah penjelasannya bagaimana satu bayang-bayang yang terpisah beribu-ribu kilometer bisa muncul begitu pendek?”.

(Kayam, 2003. SKM, halaman 4).

Dua kutipan di atas adalah sebuah penegasan akan adanya kesetiaan kepada tanah air (nasionalis) dan setia kepada pasangan. Dua karakter yang perlu ditanamkan kepada peserta didik, meski godaan demikian besar menghadang, sebagaimana tergambar dalam dialog di bawah ini :

"Kemarilah, duduk."

"Aku sedang enak di jendela sini, Jane. Ada beribu kunang-kunang di sana."

"Kunang-kunang?"

"Ya."

"Bagaimana rupa kunang-kunang itu? Aku belum pernah lihat." 
"Mereka adalah lampu suar kecil-kecil sebesar noktah."

"Begitu kecil?"

"Ya. Tetapi kalau ada beribu kunang-kunang hinggap di pohon pinggir jalan, itu bagaimana?"

"Pohon itu akan jadi pohon-hari-natal."

"Ya, pohon-hari-natal."

Marno diam lalu memasang rokok sebatang lagi. Mukanya terus menghadap ke luar jendela lagi, menatap ke satu arah yang jauh entah ke mana.

(Kayam, 2003. SKM, halaman 5).

Marno tidak meladeni ajakan Jane untuk serong tetapi ia juga tidak menjauhi dengan cara kasar yang menyebabkan orang dapat tersinggung. Ia tenang dan tetap focus pada jatidiri yang ia miliki. Ia tidak munafik. Ia adalah manusia yang memiliki karakter. Itulah Marno.

\section{Multikultural dalam Novel Salah Asuhan karya Abdoel Moeis}

Novel Salah Asuhan (Moeis, 2000) mengisahkan kisah kasih dua remaja beda bangsa, beda budaya, beda agama, beda karakter, yakni bangsa Melayu bernama Hanafi dan bangsa Eropa bernama Corrie du Busse. Kisah ini adalah contoh bahan ajar dalam pembelajaran sastra Indonesia yang pas dimana karakter multikulturalis harus dibelajarkan.

"Hanafi adalah seorang amak pribumi yang berasal dari Solok. Ibunya mengirim Hanafi ke Betawi untuk bersekolah di HBS. Hanafi dititipkan kepada keluarga Belanda, sehingga pergaulan Hanafi tidak lepas dari orang-orang Belanda. Setelah lulus sekolah di HBS, pergaulannya juga tidak lepas dari orang-orang Eropa, karena ia bekerja di Kantor BB sebagai asisten residen di Solok. Sayang, tingkah laku serta gaya hidupnya berubah menjadi kebarat-baratan, bahkan terkadang melebihi orang Belanda asli”.

Ini adalah contoh karakter yang tidak perlu ditiru.

\footnotetext{
"Selama ia bergaul dengan orang-orang Eropa dan setiap hari bersekolah di HBS, Hanafi dekat dengan gadis Eropa bernama Corrie du Busse. Dalam kesehariannya Hanafi dan Corrie memanglah sangat dekat, hubungan keduanya seperti kakak adik. Mereka sering jalan-jalan berdua, main tenis bahkan duduk-duduk sambil menikmati segelas teh berdua. Karena hubungan mereka sangat dekat, Hanafi menganggap Corrie sebagai pacar. Ia memberanikan diri untuk mengungkapkan isi hatinya kepada Corrie, namun Corrie tidak langsung menjawab. Keesokan harinya, Corrie pergi meninggalkan Solok menuju Betawi. Dikirimkan surat kepada Hanafi, yang isinya penolakan secara halus mengenai pernyataan cinta Hanafi. Corrie merasa sangat tidak mungkin menerima Hanafi, karena
} 
perbedaan budaya antara bangsa Melayu dengan bangsa Eropa. Selain itu Corrie juga ditentang oleh ayahnya jika menikah dengan orang Melayu".

Dalam parafrase di atas tampak bahwa baik Hanafi maupun Corrie belum memiliki karakter multikulturalis. Mereka menganggap etnik Barat lebih unggul daripada Melayu. Budaya Barat lebih tinggi daripada budaya Timur. Pergaulan dengan orang Barat lebih mulia dan terhormat daripada pergaulan dengan orang Melayu. Sikap rasis, antimultikulturalis seperti ini sangat berbahaya jika menular kepada siswa dan remaja, mahasiswa. Apalagi jika sudah militant. Merasa menang sendiri, unggul sendiri, hebat sendiri. Tidak dapat dimasuki paham lain yang egaliter dan demokratis. Akan membahayakan eksisitensi bangsa-bangsa di dunia jika ada yang beranggapan bahwa bangsanya lebih segalanya daripada bangsa lain.

"Hanafi memohon kepada Corrie untuk menerima ajakan pertunangannya. Karena rasa ibanya kepada Hanafi, Corrie terpaksa menerimanya meskipun Corrie harus menerima resiko, yaitu dijauhi oleh teman-teman eropanya. Seiring berjalannya waktu, rumah tangga Hanafi dan Corrie tidak harmonis. Corrie pergi ke Semarang dan meninggal karena sakit kolera, Hanafi pulang kampung dan mencoba bunuh diri”.

Kisah Hanafi dan Corrie adalah contoh bagaimana nilai-nilai multikultural tidak tertanam dengan baik. Hanafi mengira bahwa bangsa Eropa lebih tinggi derajatnya daripada bangsa Melayu dan ia pun berpindah kewarganegaraan menjadi warga Belanda untuk bisa menikah dengan Corrie. Namun ternyata bangsa Eropa tidak mau mengakui Hanafi, karena keangkuhan dan kesombongannya. Demikian juga bangsa Melayu. Hanya ibunya, Rapiah, dan Syafei anaknya yang masih menyisakan tempat untuk Hanafi. Beberapa kutipan di bawah ini adalah bukti belum adanya faham kesederajatan, karakter multikulturalis (Sudikan, 2018) :

"Itu saja sudah tidak dengan sepatunya, istimewa pula bila diketahui, bahwa seorang bangsa Bumiputera yang minta dipersamakan haknya dengan bangsa Eropah, selama-lamanya tidak boleh menghilangkan lagi hak itu dan kembali menjadi Bumiputera pula, karena tidaklah ada sesuatu fasal di dalam undang, yang boleh menggugurkan haknya sebagai bangsa Eropah". (Salah Asuhan, halaman 15).

"Yang empunya restoran menaruh keberatan ia ada di sana, dan meskipun sekalian kawankawannya, bangsa Eropah yang berpangkat-pangkat besar sudah menyatakan siapa dan pangkat apa anak Hindia itu, tapi yang empunya restoran mengangkat bidang bahunya, lalu 
berkata bahwa "direksi" restoran itu sudah mengadakan peraturan melarang orang Bumiputera masuk restoran itu”. (Salah Asuhan, halaman 20).

\section{Multikultural dalam Novel Namaku Hiroko Karya Nh Dini}

Novel Namaku Hiroko (Dini, 2000) mengisahkan perjuangan hidup gadis Jepang yang pantang menyerah dengan kemiskinannya. Meski ia tidak sekolah tinggi tetapi mampu bertahan hidup di tengah ganasnya zaman dan bahkan bias eksis dengan posisi ekonomi "high class". Saying cara yang ditempuh tidak baik (menghalalkan segala cara), yakni memanfaatkan suami sahabatnya yang kaya sebagai simpanan. Hiroko juga mengenal pemuda Indonesia bernama Soeprapto.

"Hiroko adalah gadis desa Kyusu usia 16 tahun anak sulung dari keluarga petani miskin. Ibunya meninggal saat usianya 4 tahun. Ayahnya menikah lagi dan ia mempunyai dua adik laki-laki. Karena kehidupan Hiroko yang miskin, ia hanya lulus sekolah rendah saja. Ia mencoba peruntungan, berganti-ganti bekerja sebagai pembantu rumah tangga, mulai dari rumah tangga tengkulak Tamura-san, kemudian majikan dengan pengalaman baru, mengenal cinta (dengan adik majikan bernama Sanao), bekerja di rumah keluarga konsul bahasa Perancis, hingga akhirnya diterima bekerja di sebuah toko besar dan berhasil mengambil hati salah seorang atasannya, Nakajima-san yang begitu memperhatikan dan mendorong kemajuan Hiroko dalam bekerja. Ia ikut kursus kecantikan, kepribadian, dan dansa. Dalam suatu pertunjukan tarinya Hiroko berkenalan dengan Yoshida, seorang pengusaha kapal terkenal di kota Kobe. Yoshida begitu tergila-gila sehingga apapun kemauan Hiroko selalu dipenuhinya. Hubungan mereka terhalang karena ternyata Yoshida adalah suami dari Natsuko sahabat sejatinya. Hiroko hanya sebagai wanita simpanan tanpa kejelasan status."

Sebuah potret bahwa manusia itu bukan makhluk yang sempurna.

"Hiroko berkenalan dengan Soeprapto mahasiswa asal Indonesia yang tinggal di Jepang, akan tetapi persahabatannya dengan Soeprapto tidak berjalan lama, karena Soeprapto harus kembali ke Indonesia. Nh. Dini menggambarkan perbedaan budaya Jepang dan Indonesia lewat tokoh Soeprapto. Setelah lama Soeprapto menghilang, Hiroko mendapat surat undangan yang isinya meminta Hiroko untuk berkunjung ke Indonesia. Bahkan dalam surat itu Soeprapto secara langsung berniat untuk mempersunting Hiroko, namun ia menolaknya secara halus. Hiroko tetap datang ke Indonesia memenuhi undangan Soeprapto atas saran Nakajima-san. Ia berkunjung ke beberapa tempat wisata dan begitu mengagumi keramahan bangsa Indonesia dan keluhuran budayanya. Hiroko tertarik dengan kerajinan kain batik khas Jogja. Hirokopun berniat memperkenalkan corak kain batik tersebut ke masyarakat Jepang”.

Di akhir cerita Hiroko menjadi pemilik bar Mahattan tempat dahulu ia tinggal.

Sebagian besar saham toko tempatnya bekerja pun berhasil dikuasainya. Rumah 
Nakajima-san atasan Hiroko dahulu berhasil dimilikinya, Yoshida yang membelikan rumah itu. Hiroko berhasil menjadi seorang yang sukses di kota besar. Dia bisa menyekolahkan dua adik tirinya dan membiayai kehidupan kedua orang tuanya di desa, tetapi ia memanfaatkan suami sahabatnya untuk meraih kesuksesan itu. Kegigighan hidup dengan mengenal berbagai karakter manusia perlu ditiru, tetapi cara yang dilakukan tidak perlu ditiru.

\section{SIMPULAN}

Multikultural dapat ditanamkan dengan baik melalui pembelajaran sastra. Kata kuncinya adalah toleransi. Toleransi dapat dapat diketahui dengan memperhatikan sikap seseorang terhadap orang-orang di sekitarnya. Misalnya: menghargai dan menghormati orang lain meskipun berbeda agama, suku, dan ras. Menghargai pendapat orang lain yang berbeda. Berbuat baik kepada orang lain tanpa memandang agama, suku, dan ras. Memberikan kebebasan untuk beribadah kepada setiap orang sesuai dengan kepercayaanya dan tidak melakukan intimidasi meskipun berbeda kepercayaan. Memberikan kesempatan yang sama kepada setiap orang, meskipun berbeda agama, suku, dan ras. Sikap seperti ini perlu dibelajarkan kepada siswa.

Tokoh Marno dalam cerpen Seribu Kunang-kunang di Manhattan, tokoh Soeprapto dalam novel Namaku Hiroko dan tokoh Hiroko sudah memiliki karakter multikulturalis dan perlu ditiru dengan beberapa catatan. Tokoh Hanafi dan Corrie belum memiliki karakter multikulturalis. Secara universal ketiga karya sastra Indonesia itu memiliki nilai-nilai yang layak dijadikan bahan apresiasi dalam pembelajaran sastra Indonesia.

\section{UCAPAN TERIMA KASIH}

Penelitian ini sebagian atau seluruhnya menggunakan dana penelitian Hibah Pascasarjana DRPM Dikti Tahun Anggaran 2019. Untuk itu diucapkan terima kasih kepada Prof. Ocky Karnaradjasa yang telah berkenan memberikan hibah pasca kepada unwidha Klaten. 


\section{DAFTAR PUSTAKA}

Arumdyahsari, S., W, Hs., \& Susanto, G,. (2016). "Pengembangan Bahan Ajar Bahasa Indonesia bagi Penutur Asing (BIPA) Tingkat Madya". Jurnal Pendidikan: Teori, Penelitian, dan Pengembangan, Vol. 1 No. 5, hal. 828-834. http://journal.um.ac.id/index.php/jptpp/rt/printerFriendly/6263/0

Azra, A. (2007). "Identitas dan Krisis Budaya, Membangun Multikulturalisme Indonesia" http://www.kongresbud.budpar.go.id/58\%20ayyumardi\%20azra.htm.

Budiman, M. (2008). "Lokasi Sastra dalam Sejarah dan Estetika”. Makalah semnas "Memperdebatkan Kritik Sastra". Surabaya: Fakultas Ilmu Budaya FIB, Universitas Airlangga, 12 November 2008.

Dini, N. (2000). Namaku Hiroko. Jakarta: Gramedia.

Firdaus, F, Y., \& Dian K, A. (2015). “Penanaman Nilai-nilai Multikulturalisme Melalui Pendidikan untuk Menyiasati Masalah Multikultur di Indonesia \& Malaysia. Makalah ASEAN Comparative Education Research Network Conference.

Ismawati, E. (2012). Ilmu Sosial Budaya Dasar. Yogyakarta: Ombak.

Ismawati, E. (2013). Pengajaran Sastra. Yogyakarta: Ombak.

Ismawati, E., Gunawan, B, S., \& Abdul, G, (2016). Pengembangan Model Pembelajaran Sastra Indonesia berbasis Karakter di SMA-MA-SMK Kabupaten Klaten. (Development of the teaching Learning Model of Indonesian Literature Based on Character Education in SMA/SMK in Klaten Regency). Metasastra Jurnal Penelitian Sastra. Volume 9, Nomor 2, Desember 2016. Halaman 185 - 200.

Kartika, T. (2016). "Verbal Communication Culture and Local Wisdom: The Value Civilization of Indonesia Nation". Jurnal Lingua Cultura, Vol. 10. No. 2, hlm. 89-93.

Kayam, U. (2003). Seribu Kunang-kunang di Manhattan. Jakarta: Pustaka Jaya.

Kompas.com. "Pemahaman Multikulturalisme Minim". Diakses 7 Januari 2019. https://nasional.kompas.com/read/2010/10/30/03340387/pemahaman.mul tikulturalisme.minim 
Lubis, A, Y. (2006). Dekonstruksi Epistemologi Modern. Jakarta: Pustaka Indonesia.

Moeis, A. (2000). Salah Asuhan. Jakarta: Balai Pustaka.

Ratna, N, K. (2008). Teori, Metode, dan Teknik Penelitian Sastra. Yogyakarta: Pustaka Pelajar.

Salam, A. (2008). "Mempertimbangkan Kembali Kajian Sastra Modern Indonesia". Makalah semnas "Memperdebatkan Kritik Sastra". Surabaya: Fakultas Ilmu Budaya FIB, Universitas Airlangga, 12 November 2008.

Sudikan, S, Y. (2019). Metode Penelitian Sastra Lisan. Surabaya: Pustaka Ilalang.

Sudikan, S, Y. (2018). "Revitalisasi Peran Sastra Lisan sebagai Media Pembelajaran untuk Menanamkan Nilai-nilai Karakter. Artikel Semnas Unismuh Makassar, 26 Mei 2018. http://www.unismuh.ac.id/wpcontent/uploads/2018/05/Prof-Setya-Yuwana-Sudikan.pdf .

Suparlan, P. (2002). Menuju Masyarakat Indonesia yang Multikultural. Jurnal Antropologi Indonesia. Jakarta: UI. Halaman $98-115$.

Taum, Y, Y. (2017). "Kritik Sastra Diskursif: Sebuah Reposisi” dalam Kritik Sastra yang Memotivasi dan Menginspirasi. Jakarta: Badan Pengembangan dan Pembinaan Bahasa Kemendikbud, Jakarta, 2017: hlmn 1-9.

Watson, C.W. (2000). Multiculturalism. Buckingham-Philadelphia: Open University Press.

Wikipedia Indonesia, diakses 7 Januari (2019). Mulitikulturalisme. 